\title{
ANALISIS COVER NOVEL LASKAR PELANGI KARYA ANDREA HIRATA
}

\author{
Khairunnisa $^{1)}$, Widya Agustiningrum ${ }^{2}$. \\ Program Studi Desain Komunikasi Visual \\ Fakultas Bahasa dan Seni, Universitas Indraprasta PGRI \\ Jl. Nangka No. 58 C, Tanjung Barat, Jakarta Selatan, 12530, Indonesia
}

Khairunn100@gmail.com

\begin{abstract}
Abstrak
Novel merupakan sebuah karya sastra fiksi prosa yang ditulis secara naratif, biasanya dalam bentuk cerita. Sama seperti buku lainnya yang dicetak, novel juga memiliki cover. Pada dasarnya desain cover dengan isi harus saling keterkaitan. Laskar Pelangi, merupakan novel pertama dari serangkaian tetralogi karya Andrea Hirata. Novel ini akhirnya menjadi novel dengan penjualan terbaik (Best Seller) di Indonesia dan telah diterbitkan di berbagai negara di belahan dunia. Penelitian ini bertujuan untuk meneliti bagaimana keterkaitan ilustrasi cover dengan isi cerita dan prinsip desain yang terdapat pada ilustrasi cover novel tersebut dilihat dari bentuk komposisi ilustrasi, warna dan tipografi apakah sudah menarik sehingga sesuai dengan julukan novel tersebut yang best-seller. Metode penelitian yang digunakan adalah metode kualitatif yang menyajikan data deskriptif yang bertujuan untuk menganalisis dan menafsirkan secara mendalam prinsip desain yang terdapat pada ilustrasi cover novel Laskar Pelangi tersebut dan menggunakan jenis data primer dan sekunder melalui metode observasi, dokumentasi, dan studi pustaka. Berdasarkan analisis data, dapat dijabarkan bahwa unsur-unsur visual yang terkandung dalam ilustrasi cover secara jelas menggambarkan inti cerita dari apa yang diceritakan pada isi novel Laskar Pelangi.
\end{abstract}

Kata Kunci: Novel Laskar Pelangi, Sampul, Prinsip desain.

\begin{abstract}
Novel is a literary work of prose fiction written in a narrative, usually in the form of a story. Just like any other printed book, novels also have covers. Basically, the design cover and the content must be interrelated. Laskar Pelangi, is the first novel in a series of tetralogy by Andrea Hirata. This novel eventually became the best-selling novel (Best Seller) in Indonesia and has been published in various countries around the world. This study aims to examine how the illustration is related to the content of the story and the design principles contained in the illustration cover of the novel, seen from the form of the illustration composition, colors and typography whether it is attractive so that it fits the novel's nickname best-seller. The research method used is a qualitative method that presents descriptive data which aims to analyze and interpret in depth the design principles contained in the illustration cover of the Laskar Pelangi novel and use primary and secondary data types through observation, documentation, and literature study methods. Based on data analysis, it can be explained that the visual elements contained in the illustration cover clearly illustrate the core story of what is told in the contents of the Laskar Pelangi novel.
\end{abstract}

Keywords: Laskar Pelangi Novel, Cover, Prinsip design.

Correspondence author: Khairunnisa, Khairunn100@gmail.com, Jakarta, and Indonesia

This work is licensed under a $C C-B Y-N C$ 


\section{PENDAHULUAN}

Karya sastra merupakan media yang digunakan oleh pengarang untuk menyampaikan gagasan-gagasan dan pengalamannya. Sebagai media, peran karya sastra untuk menghubungkan pikiran-pikiran pengarang untuk disampaikan kepada pembaca. Selain itu, karya sastra dapat menghibur, menambah pengetahuan dan memperkaya wawasan pembacanya dengan cara yang unik, yaitu menuliskannya dalam bentuk naratif, sehingga pesan disampaikan kepada pembaca tanpa berkesan mengguruinya. Salah satu bentuk karya sastra yang juga merupakan fiksi adalah novel.

Novel merupakan sebuah karya sastra fiksi prosa yang ditulis secara naratif, biasanya dalam bentuk cerita. Novel juga merupakan ungkapan fenomena sosial dalam aspek-aspek kehidupan yang dapat digunakan sebagai sarana untuk menuangkan cerita tentang kehidupan para tokoh dan kehidupan tertentu pada masa tertentu. Fenomena sosial dalam karya sastra yang mengalami pengolahan kepengarangan. Karya sastra selalu didasarkan pada realitas sosial (Sutardi, dkk., 2013: 482-498). Novel bisa dikatakan mirip dengan cerpen hanya saja novel lebih panjang dibandingkan dengan cerpen. Sama seperti buku lainnya yang dicetak, novel juga memiliki cover. Cover atau sampul merupakan halaman luar yang ditampilkan pada buku berisi ilustrasi maupun foto dan tipografi yang mencitrakan content (isi) yang ada didalamnya. Hal ini bertujuan untuk menunjang isi novel tersebut kemudian bisa dipahami maknanya dan tulisan yang muncul pada desain sampul atau cover novel tersebut sehingga dapat dibaca dan mudah diingat. Karena keefektifan di cover menekankan pada bentuk tampilan, selain itu juga pada isinya sehingga antara tampilan desain cover dengan isi harus saling keterkaitan.

Dalam persaingan bisnis, setiap pelakunya berusaha untuk memasarkan produknya agar konsumen berminat melihat dan kemudian membelinya. Strategi ini sangat penting bagi penerbit sehingga mereka harus mendesain cover dengan baik. Desain cover yang bagus mampu menarik perhatian orang yang melihatnya. Oleh karena itu, desain sampul atau cover sangat berperan penting dalam meningkatkan pemasaran dari suatu buku.

Desain cover novel tentu bermacam-macam, ada yang menggunakan ilustrasi, foto, bahkan ada juga yang hanya menggunakan tipografi saja. Dalam tampilan ilustrasi cover terdapat berbagai macam unsur visual yang dibuat oleh para illustrator dalam usahanya untuk menarik minat khalayak untuk membeli serta membaca buku tersebut. Unsur-unsur visual itu berupa objek (bentuk) yang diilustrasikan; konteks berupa lingkungan, orang atau mahluk lainnya yang memberikan makna pada objek; dan teks yang memperkuat makna. Berbagai macam unsur ini dapat dijelaskan dan dianalisa untuk mencari makna apa yang terkandung di dalam ilustrasi cover novel tersebut. Melalui ilustrasi cover novel hal ini bisa sedikit terjawab dikarenakan biasanya sebuah ilustrasi cover novel yang dalam hal ini peneliti maksud adalah novel Laskar Pelangi, yang menampilkan tokoh utama yang berperan dalam buku novel tersebut, sehingga pembaca bisa membentuk imajinasinya yang bisa sesuai dengan yang pengarang atau penulis novel tersebut maksudkan dalam cerita novel tersebut.

Laskar Pelangi, merupakan novel pertama dari serangkaian tetralogi karya Andrea Hirata. Buku lanjutan dari Laskar Pelangi ini, berturut-turut adalah Sang Pemimpi, Edensor, dan Maryamah Karpov. Karya tetralogi novel ini diterbitkan pada tahun 2005 oleh Penerbit Bentang. Seri novel ini akhirnya menjadi novel dengan penjualan terbaik (Best Seller) di Indonesia dan telah diterbitkan di berbagai negara di belahan dunia dengan desain cover yang berbeda-beda pula. Hal ini mendorong peneliti untuk meneliti secara dalam tentang ilustrasi cover novel Laskar Pelangi yang merupakan novel best-seller dan sukses diangkat ke dalam film yang juga setenar novelnya. Peneliti ingin meneliti bagaimana keterkaitan ilustrasi cover dengan isi cerita dan prinsip desain yang terdapat pada ilustrasi cover novel tersebut dilihat dari bentuk komposisi ilustrasi, warna dan tipografi apakah sudah menarik sehingga sesuai dengan julukan novel tersebut yang best-seller. 


\section{METODE PENELITIAN}

Metode penelitian yang digunakan peneliti dalam penelitian ini adalah metode kualitatif yang menyajikan data deskriptif. Menurut Basrowi Sadikin, penelitian kualitatif adalah jenis penelitian yang menghasilkan penemuan-penemuan yang tidak dapat dicapai dengan menggunakan prosedur-prosedur statistik atau dengan cara kuantifikasi lainnya (Sadikin, 2002). Objek penelitian ini adalah cover novel Laskar Pelangi karya Andrea Hirata yang pertama terbit tahun 2005.

Metode ini digunakan untuk menganalisis dan menafsirkan secara mendalam prinsip desain yang terdapat pada ilustrasi cover novel Laskar Pelangi tersebut dilihat dari bentuk komposisi ilustrasi, warna dan tipografi. Menurut Supriyono (2010:86), dalam Desain Komunikasi Visual, terdapat beberapa rules (aturan). Semacam gramatika atau kaidah-kaidah visual untuk mencapai komposisi yang harmonis. Berbeda dengan grammar dalam tata bahasa verbal, penyusunan gramatikal dalam Desain Komunikasi Visual menggunakan kreativitas dan orisinalitas ide. Juga terdapat istilah "Break the Rule" di mana perancang diperbolehkan melakukan terobosan kreatif yang melanggar prinsip-prinsip desain yang ada, untuk menarik lebih banyak perhatian massa. Prinsip dasar desain merupakan pengorganisasian unsur-unsur kreativitas.

Peneliti melakukan rancangan kegiatan, diantaranya dimulai dengan pengumpulan data, menganalisa data, menginterprestasi data, dan diakhiri dengan sebuah kesimpulan yang mengacu pada penganilisisan data tersebut. Analisis data yang dilakukan peneliti adalah dengan melakukan analisa ilustrasi cover novel Laskar Pelangi untuk mengetahui bagaimana keteterkaitannya antara cover atau sampul dengan isi cerita. Jenis data yang diperoleh adalah data primer dan sekunder melalui metode observasi, dokumentasi, dan studi pustaka.

\section{HASIL DAN PEMBAHASAN}

\section{Prinsip Desain}

Menurut Supriyono (2010:86), dalam Desain Komunikasi Visual, terdapat beberapa aturan rules. Semacam gramatika atau kaidah-kaidah visual untuk mencapai komposisi yang harmonis. Berbeda dengan grammar dalam tata bahasa verbal, penyusunan gramatikal dalam Desain Komunikasi Visual menggunakan kreativitas dan orisinalitas ide. Juga terdapat istilah "break the rule" dimana perancang diperbolehkan melakukan terobosan kreatif yang melanggar prinsipprinsip desain yang ada, untuk menarik lebih banyak perhatian massa. Prinsip dasar desain merupakan pengorganisasian unsur-unsur desain dengan memperhatikan prinsip-prinsip dalam menciptakan dan mengaplikasikan kreativitas. Prinsip-prinsip desain yaitu: kesatuan (unity), keberagaman (varierty), keseimbangan (balance), irama (rhythm), keserasian (harmony), skala (scale), penekanan (emphasis) (Jefkins, 1997: 245).

\section{Novel}

Novel merupakan salah satu bentuk atau genre karya sastra yang sering digunakan pengarang sebagai media penyampaian informasi berbagai persoalan dan pengamalan hidup manusia dalam segala visi dan dimensinya. Dalam novel, pengarang dapat mengemukakan berbagai persoalan dan pengamalan hidup manusia itu secara bebas, tetapi tetap harus komunikatif agar dapat dinikmati, dipahami, dan dimanfaatkan pembacanya. Novel berasal dari bahasa Italia, Novella. Dalam bahasa Jerman, Novelle, dan dalam bahasa Yunani, Novellus. Novel adalah jenis prosa yang mengandung unsur tokoh, alur, dan latar belakang yang menggelarkan kehidupan manusia atas dasar sudut pandang pengarang dan mengandung nilai hidup (Rozak dkk. dalam Hasian, 2017). Sejalan dengan itu, Nurgiyantoro (2015:13) berpendapat bahwa novel dapat diartikan sebagai karya fiksi yang dapat mengemukakan sesuatu secara lebih banyak, lebih rinci, lebih detil, dan lebih banyak melibatkan berbagai permasahan yang lebih kompleks. Unsur intrinsik adalah unsur-unsur yang membangun karya sastra itu sendiri. Unsur intrinsik sebuah novel adalah unsur-unsur yang (secara langsung) turut serta membangun sebuah cerita. Kepaduan antarberbagai unsur intrinsik inilah yang membuat sebuah novel berwujud. 


\section{Sampul Novel}

Sampul novel merupakan media untuk mengkomunikasikan pesan secara visual dan sebagai pembungkus untuk melindungi isi novel. Cover atau sampul merupakan halaman luar yang ditampilkan pada buku yang berisi ilustrasi ataupun foto dan tipografi yang mencitrakan content (isi) yang ada didalamnya. Hal ini bertujuan menunjang isi buku tersebut kemudian bisa dipahami maknanya dan tulisan yang muncul pada desain sampul atau cover buku tersebut sehingga dapat dibaca dan mudah diingat. Desain cover sangat penting didesain secara indah dan artistik. Desain cover yang bagus mampu menarik perhatian orang yang melihatnya, oleh karena itu desain sampul atau cover sangat berperan penting dalam meningkatkan pemasaran dari suatu buku.

\section{Anatomi Desain Sampul Novel Laskar Pelangi :}

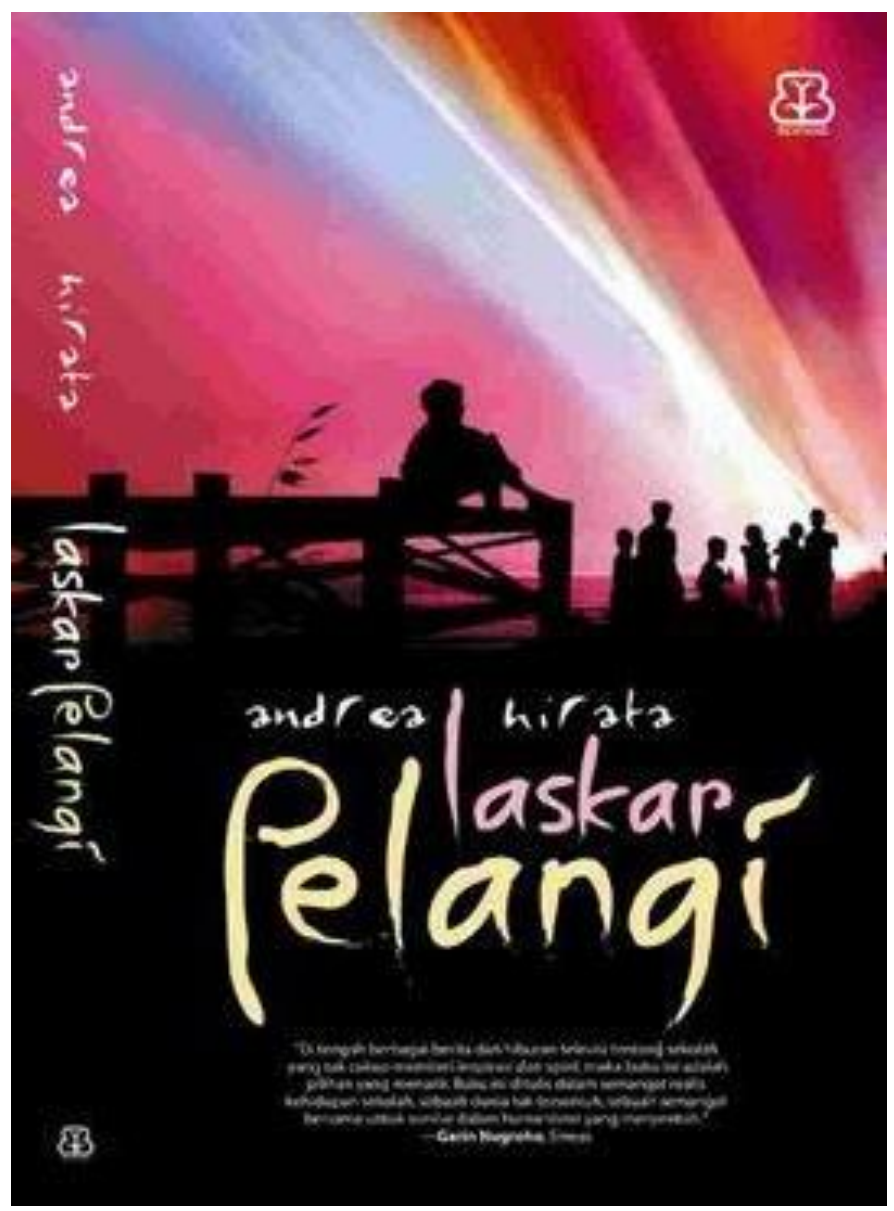

Gambar 1 Desain Sampil Novel Laskar Pelangi

\section{Layout Desain}

Sampul novel Laskar Pelangi memiliki layout dan sistematika pembacaan horizontal dari atas ke bawah, atau Picture Window Layout - Tampilan gambar yang besar menjadi ciri utama tata letak ini, dan di ikuti dengan headline, keterangan gambar hanya memiliki porsi yang kecil. Jenis tata letak yang menggunakan huruf yang besar sebagai unsur utama, gambar yang digunakan hanya berfungsi sebagai unsur pendukung saja. Layout ini diterapkan dari atas ke bawah. 


\section{Warna}

Semua arti warna ini melambangkan isi pesan novel karena sampul adalah visualisasi yang mencitrakan isi content. Dan beberapa warna di bawah ini melambangkan pesan yang akan disalurkan penulis kepada pembaca.

\section{Merah Muda / Pink:}

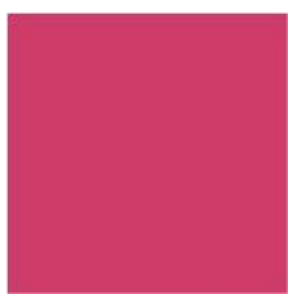

Merah muda adalah warna yang cukup berbeda dan tingkat intensitasnya dapat memberikan kesan manis mengindikasikan bermuda, energi, seru dan menyenangkan.

\section{Orange:}

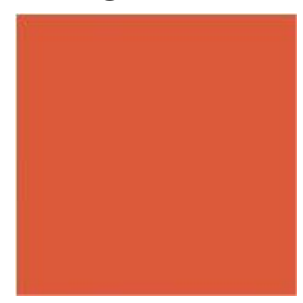

Mencampurkan kehangatan warna merah dan keoptimisan warna kuning, orange mengkomunikasikan aktifitas dan energi. Positifnya adalah memberikan tambahan energi, kreativitas, keunikan, stimulasi, sosial, kesehatan, aktivitas. Negatifnya adalah kegilaan, trend, berisik.

\section{Merah:}

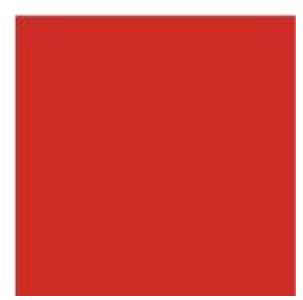

Merah itu tebal, berenergi, dan warna yang hidup yang menyimbolkan kekuatan, kepercayaan diri dan kekuatan. Positifnya yaitu semangat, cinta, darah, energi, antusiasme, panas, kekuatan. Sementara, negatif yaitu agresif, kemarahan, perang, revolusi, kekejaman, ketidaksopanan.

\section{Kuning:}

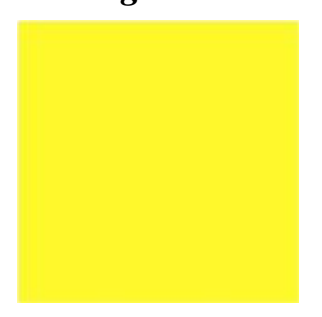

Warna kuning membawa senyuman dan mengkomunikasikan keceriaan, keramahan, kesenangan dan energi. Warna kuning juga bisa diasosiasikan dengan kejernihan mental dan kepintaran. Positifnya yaitu intelek, kebijaksanaan, optimisme, cahaya, kegembiraan, idealisme. Sementara, negatifnya yaitu kecemburuan, pengecut, ketidakjujuran, waspada.

\section{Biru:}

Biru adalah warna universal yang sering dipilih, mungkin karena kualitasnya yang serba guna untuk menyampaikan kehandalan, dapat dipercaya. Warna biru juga diapresiasi untuk ketenangan dan kualitas harmoni yang berasosiasi dengan laut dan langit. Meski pun begitu, diasosiasikan dengan perasaan emosi seperti mengekspresikan kesedihan atau depresi. Makna positifnya yaitu pengetahuan, kesejukan, kedamaian, maskulin, kontemplasi, kesetiaan, keadilan, intelektual. Sementara, negatifnya adalah depresi, dingin, kelesuan. Warna biru pada seragam menyimbolkan kesetiaan dan kepercayaan. 


\section{Ungu:}

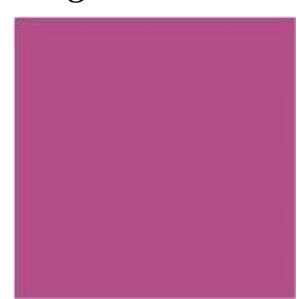

Hitam:

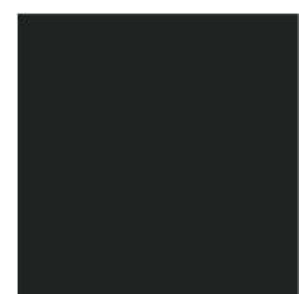

Hitam diasosiasikan dengan malam dan kematian. Positifnya adalah kekuatan, kekuasaan, berat, kemewahan, elegan, formal, serius, bergengsi, kesunyian, misteri. warna hitam memberi efek meningkatkan kepercayaan diri dan kekuatan, diasosiasikan dengan kerahasiaan. Hitam bisa dianggap sebagai warna yang serius. Mewakili kekuatan, kemewahan, kecanggihan dan eksklusif .

\section{Putih:}

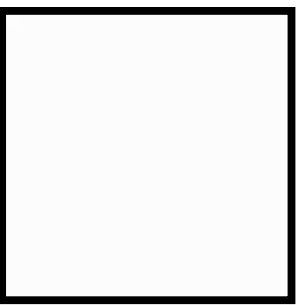

\section{Tipografi}

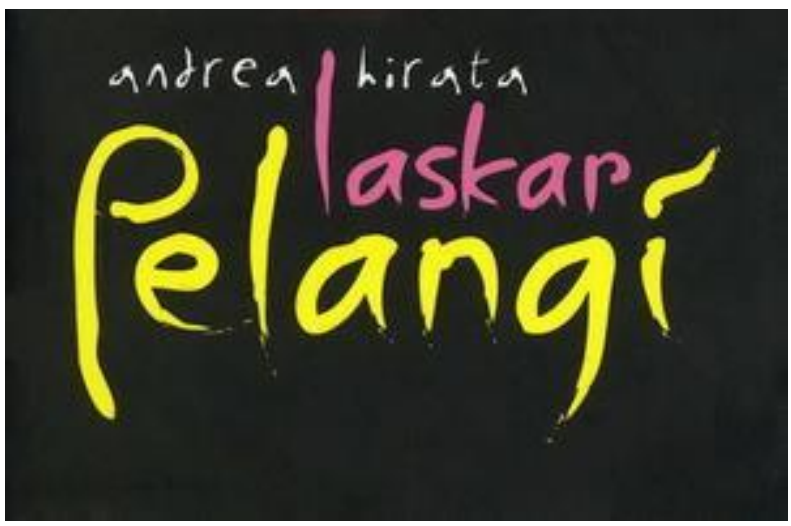

Gambar 2 Tipografi dalam Sampul Novel Laskar Pelangi

Tipografi merupakan seni memilih dan menata huruf dengan pengaturan penyebarannya pada ruang-ruang yang tersedia, untuk menciptakan kesan khusus sehingga akan membantu pembaca menemukan karakter dan makna dari logo.

Di dalam sampul novel Laskar Pelangi terdapat teks berupa nama penulis dan judul novel, “Andrea Hirata Laskar Pelangi” menggunakan jenis tipografi Sans Serif, dan tipografi cursive.

Font ini diberi kesan modern, umum, simple atau mudah dibaca layaknya tulisan tangan yang dapat mencerminkan ekspresi spontan, memberikan citra retro atau klasik, beralur, perasaan masa lalu, daya tarik modernitas. Font ini dibuat untuk menuliskan kata "Andrea Hirata Laskar Pelangi" atau judul dan nama penulis dalam novel. 
Pada nama penulis (Andea Hirata) berwarna putih yang memberi warna hidup di antara warna ilustrasi lainnya, warna putih sendiri dipilih karena menggambarkan kesederhanaan, kemurnian, tidak bersalah dan kesempurnaan. Pada judul (Laskar) berwarna ungu, laskar sendiri berarti sekelompok atau serdadu atau pasukan (Kamus Besar Bahasa Indonesia), dan diisyaratkan dengan warna ungu yang memiliki arti kebijaksanaan, imajinasi, keajaiban, tingkatan, dan inspirasi, dan laskar wujud dari sekelompok imajinasi atau keajaiban yang dimiliki para anak anak laskar pelangi.

Kata (Pelangi) yang bisa dikatakan sebagai benda langit yang memiliki macam-macam warna. Diberi warna Kuning yang dapat diibaratkan sebagai pembawa senyuman dan mengkomunikasikan keceriaan, keramahan, kesenangan, dan energi. Warna kuning juga bisa diasosiasikan dengan kejernihan mental dan kepintaran. Dan bisa disimpulkan bahwa laskar pelangi yang ingin penulis (Andea Hirata) sampaikan adalah sekelompok anak-anak yang memiliki keajaiban, dan mimpi yang tinggi setinggi langit yang mampu membawa memberikan senyuman, kebahagian, dan keceriaan.

\section{Ilustrasi}

\section{Siluet}

Siluet figur anak di dermaga kayu yang sedang menatap sekolompok anak didepannya. Dan siluet sekelompok yang sedang berkumpul menandakan adalah dia sebagai tokoh utama (Ikal) dalam novel Laskar Pelangi dan anak-anak lainnya adalah anggota Laskar Pelangi.

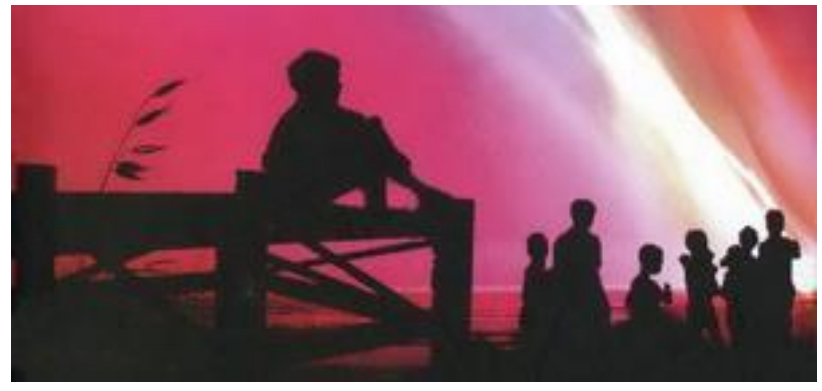

Gambar 3 Ilustrasi Siluet dalam Sampul

\section{Langit senja dengan awan berwarna pelangi}

Senja dapat diartikan sebagai waktu, atau tanda bergantinya hari. Setelah hari ini akan nada hari esok yang menantimu, pada saat itu (senja) akan memperlihatkan langit yang sangat indah dengan warnanya yang bermacam-macam, lalu berganti menjadi malam yang sepi dan tenang. Seperti para Laskar Pelangi, anak-anak yang bermacammacam dari segi sifat karakter perilaku dan wajah, tetapi mereka sama-sama mempunyai satu tujuan yaitu mengejar mimpi hingga setinggi langit.

Dan pesan yang ingin disampaikan dalam novel ini adalah "Hidup itu penuh warna dan bersyukur akan membuatnya lebih indah". Dimulai dari warna yang suram hingga warna yang paling cerah

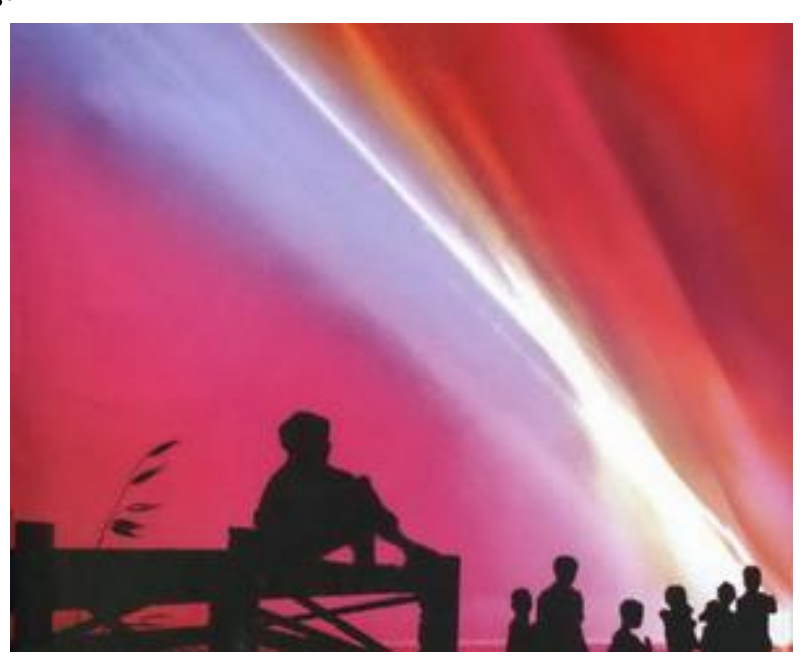

Gambar 4 Ilustrasi Langit Senja dalam Sampul ceria. Jadi, warna pelangi dapat diartikan sebagai keceriaan kehidupan masa kecil bersama temantemannya di sekolah yang selalu menyambut gembira pelangi setelah hujan. Seperti menyambut datangnya hari esok. 


\section{Target Khalayak}

Khalayak adalah kelompok manusia yang dijadikan sasaran komunikasi, sedangkan sasaran adalah tujuan dari kegiatan untuk mencapai tujuan utama (Kamus Besar Bahasa Indonesia, 2003) jadi khalayak sasaran ialah sekelompok masyarakat yang dijadikan sasaran yang bertujuan untuk mencapai target yang sudah ditentukan. Khalayak sasaran dari novel Laskar Pelangi adalah remaja hingga dewasa dari usia 14 sampai 18 tahun, dan remaja awal 18 sampai 25 tahun. Dipilihlah remaja hingga dewasa yang memiliki sifat suka membaca, serta memiliki cara pandang yang cukup luas. Pemilihan ini sesuai dengan sasaran demografis dimana emosi dari remaja hingga dewasa lah yang nantinya akan dimainkan. Mereka sedang mengalami pendewasaan diri meliputi fisik dan emosi dan juga mental (Hurlock, 1992). Serta pada masa ini cenderung memiliki rasa keingintahuan besar pada hal-hal yang bersifat baru atau pembaruan, yang dimana keadaan emosi merekalah yang menjadi dasar dari sasaran media ilustrasi.

\section{Segmentasi}

Consumer Insight, Maulana (2009) mengatakan jika consumer insight merupakan tahapan dari proses pencarian pencarian yang mendalam terhadap latar belakang, cara berfikir dan juga perilaku dari seseorang yang memiliki hubungan dengan produk serta komunikasi dari iklannya. Maka dari itu untuk mencari isi pikiran dari khalayak sasaran, maka dicarilah remaja pertengahan dan dewasa yang memiliki tingkat minat baca yang tinggi, dan biasanya remaja dan orang dewasa perkotaan, mereka cenderung lebih menyukai novel yang tidak selalu berbau drama percintaan, mistik ataupun horror.

\section{Targeting}

Target pasar adalah memilih satu atau beberapa segmen konsumen yang akan menjadi fokus kegiatan-kegiatan pemasaran dan promosi, sehingga target pasar yang dibidik oleh novel Laskar Pelangi adalah anak remaja awal dan dewasa yang senang membaca novel. Dengan kisah yang inspiratif dan menyajikan keindahan Pulau Belitong yang jarang tersentuh oleh media, hal tersebut menjadikan keunggulan menarik bagi remaja dan orang dewasa yang suka membaca novel menarik dan inspiratif.

\section{Positioning}

Positioning novel Laskar Pelangi adalah kisah yang memberikan banyak pembelajaran tentang persoalan nasionalis-religius Indonesia, yang sesuai dengan Pancasila. Kisahnya yang mengandung nilai-nilai pendidikan, spiritual, moral dan universal adalah hal yang mendukung diferensiasi dari sisi konteks atau isi dalam positioning novel ini. Sedangkan diferensiasinya dari sisi konteks novel Laskar Pelangi ini merupakan kisah kalangan akar-rumput di Pulau Belitong yang pluralis. Suatu entitas masyarakat yang khas Indonesia dan masih jarang atau belum pernah diungkap sebelumnya. Selain itu, brand positioning Laskar Pelangi sebenernya telah lama tercipta di masyarakat dengan kepopuleran novelnya.

\section{SIMPULAN}

Analisis visual ilustrasi cover novel Laskar Pelangi bertujuan untuk menganalisis dan menafsirkan secara mendalam prinsip desain yang terdapat pada ilustrasi cover novel dengan kaitannya terhadap isi cerita di dalam novel tersebut. Berdasarkan analisis data, dapat dijabarkan bahwa unsur-unsur visual yang terkandung dalam ilustrasi cover secara jelas menggambarkan inti cerita dari apa yang diceritakan pada isi novel Laskar Pelangi tentang perjuangan sepuluh anak kampong di Pulau Belitong, Sumatera, yang ingin bersekolah, dengan tekad yang kuat untuk belajar. Ilustrasi cover juga menggambarkan siluet figur seorang anak lainnya didermaga kayu yang sedang menatap sekelompok didepannya. Siluet sekelompok anak yang sedang berkumpul menandakan adalah dia sebagai tokoh utama (Ikal) dalam novel Laskar Pelangi dan anak-anak lainnya adalah anggota Laskar Pelangi. Dan langit senja dengan awan yang bewarna seperti pelangi menggambarkan para Laskar Pelangi, anak-anak yang bermacam-macam dari segi sifat karakter perilaku dan wajah, tetapi mereka sama-sama mempunyai satu tujuan yaitu mengejar mimpi hingga setinggi langit. Mereka juga adalah anak-anak yang memiliki keajaiban, dan mimpi yang tinggi setinggi langit yang mampu membawa memberikan senyuman, kebahagian, dan keceriaan. Pesan yang ingin disampaikan dalam novel ini adalah "Hidup itu penuh warna dan 
bersyukur akan membuatnya lebih indah". Dimulai dari warna yang suram hingga warna yang paling cerah ceria. Jadi, warna pelangi dapat diartikan sebagai keceriaan kehidupan masa kecil bersama teman-temannya di sekolah yang selalu menyambut gembira pelangi setelah hujan. Seperti menyambut datangnya hari esok.

Penggunaan bentuk, warna dan tipografi pada ilustrasi cover novel Laskar Pelangi mempunyai makna-makna tertentu yang saling berkaitan satu sama lain dan tentunya berkaitan erat dengan cerita novel tersebut.

\section{DAFTAR PUSTAKA}

Depdikbud. (2003). Kamus besar bahasa Indonesia. Jakarta: Balai Pustaka

Hasian, I. (2017). Analisis desain sampul novel karangan Ayu Utami ditinjau dari perspektif desain komunikasi visual. Magenta Official Journal STMK Trisakti, 1(02), 157-173.

Hirata, A. (2007). Laskar pelangi. PTS Millennia.

Hurlock, E. B. (1992). Psikologi perkembangan: Suatu pendekatan sepanjang rentang kehidupan. Jakarta: Erlangga.

Jefkins, F. (1997). Periklanan. Jakarta: Erlangga.

Maulana, A. E. (2009). Consumer insight via enthnography. Jakarta: Erlangga

Nurgiyantoro, B. (2015). Teori pegkajian fiksi. Yogyakarta: Gadjah Mada University Press

Sadikin, B. (2002). Metode penelitian kualitatif perspektif mikro. Surabaya: Insan Cendekia

Supriyono, R. (2010). Desain komunikasi visual teori dan aplikasi. Yogyakarta: Andi.

Sutardi, H. J. W., Winarni, R., \& Wardani, N. E. (2013). The study of genetic structuralism, gender, and values of education in trilogy novel Gadis Tangsi by Suparto Brata. Online International Interdisciplinary Research. 